\title{
Relations between adrenocortical and nociceptive responses toward acute stress in individual dairy cows
}

\author{
M. S. Herskin ${ }^{1}$ and L. Munksgaard \\ Department of Animal Health and Welfare, \\ Danish Institute of Agricultural Sciences, Research Centre Foulum \\ P.O. Box 50, DK-8830 Tjele, Denmark
}

\begin{abstract}
Effects of acute stressors on adrenocortical and nociceptive responses were examined in 24 dairy cows kept in tie-stalls, using 15-min of isolation in novel surroundings (ISOL), fixation by head in home stall (FIX), and provision of novel neighbours/stall (NEIGH) as acute stressors as well as a control treatment $(\mathrm{CON})$. Each cow was exposed to one treatment daily. Within treatments capable of inducing significant adrenocortical responses, no relations between the adrenocortical reactivity and the nociceptive changes were found. The results suggest that adrenocortical and nociceptive responses of individual dairy cows toward acute stress are independent components of the responses toward challenging events.
\end{abstract}

KEY WORDS: cattle, cortisol, hypoalgesia, isolation, laser, pain

\section{INTRODUCTION}

Nociception is the sensory proces activated by receptors which are sensitive toward tissue-damaging stimuli (Jensen et al., 2003). Nociceptive changes are a component of the fundamental behavioural and physiological response toward stressors (Kavaliers, 1988), facilitating the expression of adaptive defensive behavioural responses (Bolles and Fanselow, 1980). Many animal species show increased nociceptive thresholds (hypoalgesia) after exposure to environmental stimuli, often associated with stress or aversion (Yamada and Nabeshima, 1995).

In dairy cows, exposure to acute stress can lead to stressor specific nociceptive and adrenocortical responses (Herskin, 2004). However, activation of the

\footnotetext{
${ }^{1}$ Corresponding author: e-mail: MetteS.Herskin@agrsci.dk
} 
hypothalamus-pituitary-adrenal axis (HPA-axis) is not necessary for the induction of stress-induced nociceptive changes (Rushen and Ladewig, 1991). In the study of individual differences, nociception has received very little attention, and it is not known whether stress-induced nociceptive responses of individual animals relate to their adrenocortical responses toward the same acute stressors.

The aim of the present experiment was to examine relations between adrenocortical reactivity toward acute stress of individual dairy cows and nociceptive responses induced by the same acute stressors.

\section{MATERIAL AND METHODS}

\section{Animals and feeding}

Twenty-four Danish Holstein cows $(89 \pm 4$ days pp and with a mean lactation number of 2.0 \pm 0.2 ) from the resident herd were used. The cows were tethered with neck-bar ties, milked twice daily according to the routines in the barn and fed twice daily with a total mixed ration. Sufficient food was given to allow ad libitum intake.

\section{Experimental design}

Effects of acute stress on adrenocortical and nociceptive responses were investigated using four treatments (described by Herskin, 2004): a. control: undisturbed in home stall (CON); b. novel stall and neighbours (NEIGH); c. fixation by head in home stall (FIX); and d. social isolation in novel surroundings (ISOL). Each treatment lasted $15 \mathrm{~min}$. Before and after treatment blood was sampled by puncture of the jugular vein. The nociceptive thresholds (latency to move leg, sec) and type of nociceptive responses were determined using laser technique (Herskin et al., 2003). Each cow was tested daily for four successive days, and exposed to one treatment each day.

\section{Statistical analysis}

Between treatments, the Mixed Procedure of SAS was used to compare adrenocortical responses. Within treatments inducing significant increase in the plasma concentration of cortisol, FIX and ISOL, the changes in nociceptive thresholds and nociceptive responses after treatment were correlated with the changes in plasma concentration of cortisol using Spearman Correlation Coefficient.

\section{RESULTS}

\section{Adrenocortical responses}

Exposure to treatments led to an increased concentration of cortisol for FIX and ISOL compared with CON and NEIGH as well as a higher concentration for ISOL than FIX $(\mathrm{P}<0.001)$ (Figure 1). 


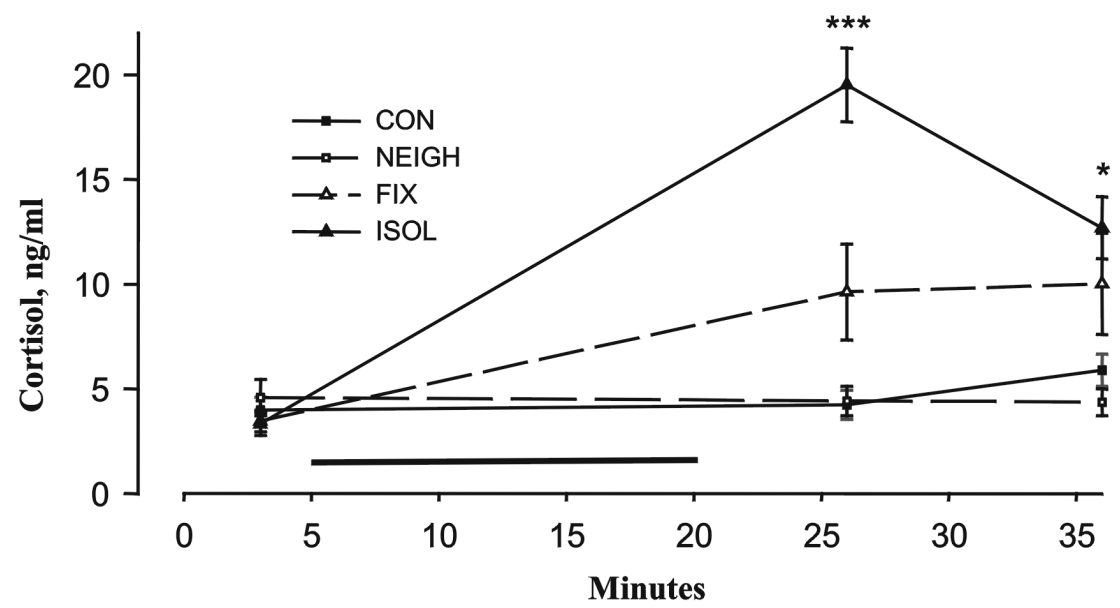

Figure 1. The plasma concentration of cortisol $(\mathrm{ng} / \mathrm{ml})$ obtained by puncture of the jugular vein before and after exposure to the four treatments (duration indicated by black bar)

\section{Nociceptive responses}

Within treatment nociceptive changes were observed for CON, FIX and ISOL. CON led to a decrease in the latency to move the exposed leg $(\mathrm{P}<0.05)$ (Figure 2). When exposed to ISOL the latency to move the leg after laser stimulation increased $(\mathrm{P}<0.01)$ (Figure 2). FIX led to reduced percentage of responses observed as kicking ( $44.5 \pm 5.0$ vs $35.5 \pm 4.5 \%$; $\mathrm{P}=0.06)$, while the other treatments did not affect the types of nociceptive responding.
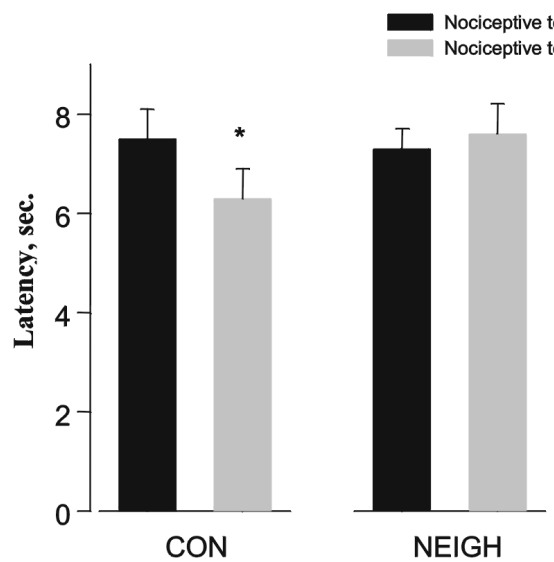

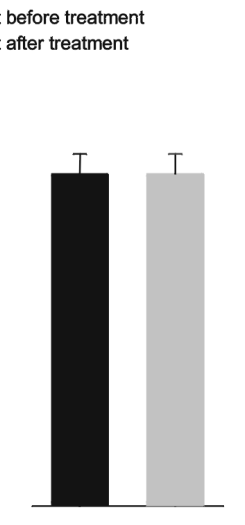

FIX

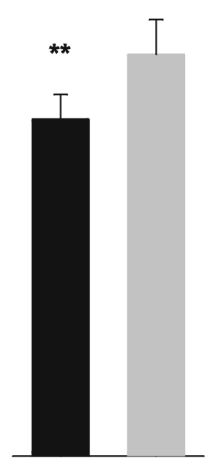

ISOL

Figure 2. Nociceptive thresholds of the dairy cows before and after exposure to each of the four treatments 


\section{Relations between adrenocortical reactivity and nociceptive changes}

Within treatments the correlations between nociceptive threshold and adrenocortical reactivity were: FIX: $r_{s}=-0.16 ; P>0.10 ; N=22$, ISOL: $r_{s}=-0.24$; $\mathrm{P}>0.10 ; \mathrm{N}=20$, respectively. Correlations between the changes in nociceptive responses and adrenocortical reactivity were: FIX: $\mathrm{rs}=-0.21 ; \mathrm{P}=0.35 ; \mathrm{N}=22$, ISOL: $r s=-0.38 ; \mathrm{P}=0.10 ; \mathrm{N}=20$, respectively.

\section{DISCUSSION}

ISOL and FIX were the only treatments able of inducing adrenocortical responses. However, no relations between the adrenocortical and nociceptive responses of individual dairy cows toward ISOL or FIX were found. Activation of the HPA-axis is not necessary for the induction of stress-induced hypoalgesia (Herskin, 2004) and we found no evidence for a relation between adrenocortical and nociceptive reactivity toward acute stress in individual dairy cows.

\section{CONCLUSIONS}

The results of the present study suggest that adrenocortical and nociceptive responses of individual dairy cows toward acute stress are independent components of the response toward challenging situations.

\section{REFERENCES}

Bolles R.C., Fanselow M.S., 1980. A perceptual-defensive recuperative model of fear and pain. Behav. Brain Sci. 3, 291-323

Herskin M.S., Müller R., Schrader L., Ladewig J., 2003. A laser-based method to measure thermal nociception in dairy cows: short-term repeatability and effects of power output and skin condition. J. Anim. Sci. 81, 945-954

Herskin M.S., 2004. Responses of dairy cattle toward acute stress and novelty - behaviour, physiology and nociception. PhD. Thesis, Royal Veterinary Agricultural University. Copenhagen (Denmark), pp. 130

Jensen T.S., Dahl J.B., Arendt-Nielsen L., 2003. Pain - a Textbook (in Danish). FADL, Copenhagen, pp. 396

Kavaliers M., 1988. Evolutionary and comparative aspects of nociception. Brain Res. Bull. 21, 923-931

Yamada K., Nabeshima T., 1995. Stress-induced behavioural responses and multiple opioid systems in the brain. Behav. Brain Res. 67, 133-145 